\title{
As representações sociais da água por crianças e adolescentes de Joinville
}

\author{
Social representation of water by kids and teenagers of Joinville
}

\author{
Maria Luiza Schwarz'; Joceline Bonatti"; Roberta Barros Meira'II
}

\begin{abstract}
RESUMO
O desenho é uma linguagem que expressa sentimentos e opiniões, revelando o que o seu autor pensa sobre determinada temática. A água e sua importância na vida do ser humano e da biodiversidade, a maneira como ela é utilizada são questões que vêm sendo discutidas no contexto escolar devido a sua grande influência na vida em sociedade. Este artigo pretende identificar as representações sociais da água pelas crianças e adolescentes de diferentes faixas etárias em Joinville/SC. Foram analisados 192 desenhos elaborados a partir do enunciado "desenhe tudo o que lhe vem em mente quando falamos a palavra 'água'". Neste sentido, primeiramente as imagens foram classificadas quanto aos elementos representados, somando um total de 1865 itens. Posteriormente, a abordagem foi dividida em cinco temas, conforme o grau de incidência nas representações. A água como importante elemento para os seres vivos; a chuva como elemento importante para o abastecimento de rios e cachoeiras; mudanças no estado físico e o desperdício de água; a água como atividade lúdica e de momentos de lazer; poluição das águas. Os resultados denotaram uma visão utilitarista da água. As crianças e os adolescentes percebem a água mais como um bem de consumo, o que indica necessidade de abordagens que enfoquem a água como Patrimônio Comum da Humanidade.
\end{abstract}

Palavras-chave: Desenho-infantil; Patrimônio-comum-da-humanidade; Visão-utilitarista

\section{ABSTRACT}

The drawing is a language that expresses feelings and opinions, revealing what the author thinks about certain subject. The water and its importance for the human being and for biodiversity, and the manner how it's used are questions wich are being discussed on the scholar context due to its big influence on life in society. This article pretends to identify the social representations of water by kids and teenagers of different age groups in Joinville- SC. It was analyzed 192 draws, made from the statement "draw everything comes to your head when we say the word 'water'". In this sense, firstly the images were classified by the elements represented, totaling 1865 items. After, the approach was divided in five themes, according to the degree of incidence of the representations. The water as an important element for the living beings; rain as an important element for the supply of rivers and waterfalls; changes in physical condition and waste of water; the water as a ludic activity and moments of pleasure; pollutions of waters. The results denoted a utilitarian vision of water. The kids and teenagers realized that water as a commodity; which indicates the need of approaches that focus the water as a common heritage of humanity.

Keywords: Child-drawing; Common-heritage-humanity; Utilitarian-view

' Licenciada em Geografia pela Universidade da Região de Joinville, possui doutorado em Geografia Humana e Ambiental pela Université de Montréal, Pós-doutorado em Geografia Humana. E-mail: maria.schwarz@univille.br ORCID: https://orcid.org/0000-0002-2403-4593

" Graduado em Pedagogia pela Universidade da Região de Joinville. Professor do Colégio Machado de Assis. E-mail: jocelinebonatti@yahoo.com.br ORCID: https://orcid.org/0000-0003-2549-8602

III Bacharel e licenciada em História pela Universidade Federal Fluminense, mestrado e doutorado em História Econômica pela Universidade de São Paulo. Docente do Mestrado em Patrimônio Cultural e Sociedade da Universidade da Região de Joinville - Univille. E-mail: jocelinebonatti@yahoo.com.br ORCID: https://orcid.org/0000-0001-7739-216X 


\section{INTRODUÇÃO}

Num contexto de modernidade em que a problemática ambiental se acentua, um dos temas discutidos tem sido a água e sua importância como patrimônio comum da humanidade. Diante da escassez deste recurso, as atenções se voltam para a necessidade de preservação e as discussões são muitas, tanto do ponto de vista jurídico (DA SILVA CARDOSO, 2006; NASCIMENTO-SCHULZE, 2000; SOUZA, 2012), dos Direitos Humanos (JACOBI; EMPINOTTI; SCHMIDT, 2016; ), das questões ambientais (PENA-GARCIA, 2017; GARRÉ, HENNING, 2017), das políticas públicas (HASSAN, 2008; FRÖHLICH，2012; EMPINOTTI; JACOBI; FRACALANZA, 2016), quanto das discussões sobre as questões econômicas (SCHMITZ; BITTENCOURT, 2017; TIBERGHIEN, 2012; ANTONELLI et al., 2012; BAECHLER, 2013) e sociais (LASSERRE, 2006; MACHADO, 2003).

A distribuição desigual da água, o acelerado crescimento da população mundial, sua crescente demanda, o fracasso do Estado para administrar as questões de sustentabilidade (PENA-GARCIA, 2007), que é a utilização consciente do recurso, sem prejudicar o abastecimento para as gerações futuras.

Um apelo para ações rápidas sobre o uso sustentável da água foi feito na abertura da oitava edição do Fórum Mundial da Água, sediado em Brasília entre os dias 19 a 23 de março de 2018. Esse discurso foi feito por inúmeros especialistas, assim como pela Organização das Nações Unidas-ONU e políticos que estavam presentes. Nesse mesmo evento foi lançado um documento em que salienta a importância de Soluções Baseadas na Natureza (SBN) para a gestão da água: "Florestas, zonas úmidas e campos, bem como solos e áreas de plantio, quando gerenciadas de forma adequada, exercem papéis importantes na regulação da qualidade da água" (ONU, 2018, p. 5). Os debates estão voltados aos desafios da gestão, bem como para a melhoria da disponibilidade e da qualidade da água, reduzindo os riscos e desastres hídricos. Em nenhum momento desse documento, os autores descrevem a água como patrimônio comum da humanidade, evitando assim discussões contraditórias e polêmicas sobre a gestão do recurso. Há necessidade de 
sensibilizar a população sobre esses problemas e sobre as práticas, não somente do consumo consciente e eficaz, mas para soluções baseadas na natureza.

Os desenhos das crianças e adolescentes são úteis e fornecem preciosas informações nas avaliações das percepções ambientais das crianças (BARRAZA 1999). Recolher as informações sociais das crianças através dos desenhos é um meio bastante fácil (KING, 1995) e eficaz (SCHWARZ et al., 2016). As crianças gostam de desenhar e não demonstram nenhum sinal de tensão, diferente de quando elas são confrontadas a responderem questionários (BARRAZA, 1999). A criança desenha para se divertir (LUQUET, 1969), apesar que ela pode expressar as noções complexas do mundo e da ciência através de imagens cotidianas e familiares (SCHWARZ et al., 2016).

Luquet (1969) explica que os desenhos infantis estão baseados num modelo mental interno e que são cinco as etapas do desenvolvimento: (1) Realismo fortuito (18 meses a 2 anos) -esses primeiros rabiscos, segundo o autor, demonstram a consciência do modelo e é a fase de um exercício para que ocorra um aumento da coordenação do olho e da mão. Ela realiza traços sem um objetivo preciso; (2) Realismo falhado (2 a 3 anos) -os rabiscos agora são reconhecidos para os outros. Mas as crianças dessa idade não conseguem coordenar as partes do desenho; (3) Realismo simbólico (3 a 4 anos) -as crianças começam a colocar em relação os detalhes de um desenho. Muitos desenhos nesses estágios parecem estar baseados em simples fórmulas e esquemas; (4) Realismo intelectual (5 a 7 anos) -os desenhos feitos nesse estágio possuem elementos que a criança sabe que existem, mesmo que não estejam visíveis. As ilustrações são chamadas desenhos de "transparência", como por exemplo, podem desenhar os peixes no fundo do oceano, animais no interior dos troncos das árvores ou os pássaros dentro de seus ninhos; (5) Realismo visual (8 anos e mais) - as crianças começam a tirar partido de um ponto de vista em particular, utilizando proporções e estabelecendo relações em consequência.

Essa classificação de Luquet contribuiu muito para a ciência cognitiva e serviu de influência para Piaget. $O$ desenho tem um papel primordial na promoção do desenvolvimento cognitivo (PIAGET, 1987). É cada vez mais frequente a utilização dos 
desenhos infantis como instrumento para recolher conhecimentos científicos e os valores sobre o meio ambiente no Brasil e no mundo, como nas pesquisas recentes de Dai (2011), onde ela analisa as representações das crianças taiwanesas sobre a natureza, verificando que as crianças excluem o homem das representações. Essa é uma questão grave, pois se a criança não se integra nesses ecossistemas, não contribuirá para sua conservação. Quando Donna King (1995) evocou: "você tem que salvar o planeta" para jovens estadunidenses entre 5 e 15 anos, verificou que $87 \%$ deles estavam conscientes da crise ambiental e isso foi visto através dos desenhos deles.

Schwarz (2007) em uma pesquisa feita no Colégio Santos Anjos de Joinville, solicitou que as crianças e adolescentes desenhassem tudo que lhes vinha em mente quando se falava na Floresta Atlântica. Esses jovens entre 6 a 15 anos desenharam a floresta em segundo plano, com aparência uniforme, não retrataram a riqueza de espécies de árvores e de outras plantas do rico ecossistema. A evocação da Floresta Atlântica foi feita longe da mesma, sem o contato direto, mas viam resquícios dela pela janela da escola onde foram aplicados os desenhos e ela está bastante presente nas paisagens que envolvem a área urbana da cidade, mas que é adentrada por poucos. Bowker (2007) analisou o desenho de 30 crianças entre 9 a 11 anos, antes e depois de participarem de um projeto chamado Eden. Essas crianças desenharam uma floresta tropical úmida antes de visitarem o bioma e, depois. No primeiro desenho, retratavam árvores com frutos dourados, uma floresta uniforme, como nos desenhos analisados por Schwarz (2007). Após a visita, as representações dessas crianças eram mais ricas em detalhes, como as gotas escorrendo das folhas, a representação de animais nativos que povoavam a floresta, as cores e texturas, entre outros. Pode-se afirmar depois desses estudos, a importância da utilização dos desenhos para a análise de conhecimentos científicos sobre o meio ambiente e sobre questões especificas atribuídas ao mesmo.

Poucos são os estudos que utilizaram os desenhos na análise dos conhecimentos de crianças e adolescentes sobre a temática água, embora existam alguns estudos que utilizam outros instrumentos como a enquete sobre a água 
realizada por Durif-Bruckert (2013), nos estudos sobre os conhecimentos de alunos na compreensão de atividades sobre ciclo da água realizados por Tytler; Peterson e Prain (2007). Silva, Aguiar-Junior e Belmiro (2015) analisaram os desenhos infantis nos processos de construção de sentidos em uma sequência de ensino sobre o ciclo da água. A questão da água num contexto geral, principalmente ambiental, foi realizado por Pérez e Crispin (2008) com crianças de Puebla no México. Os autores verificaram que a água para essas crianças tem primeiramente valor lúdico, contrapondo com os resultados de uma outra pesquisa realizada também no México, mas na região semiárida do Ejido Francisco Medrano-Tula, onde as crianças querem a chuva para encher os rios e cachoeiras e desejam ter uma torneira no quintal da casa (SCHWARZ et al. 2016).

Os conhecimentos das crianças e adolescentes sobre a água emergem das práticas vivenciadas diariamente, por essa razão, são excelentes subsídios para estudos dentro da perspectiva da Abordagem Temática Freiriana, onde o autor salienta a importância de se trabalhar com os temas atuais (FREIRE, 1994). Sendo assim, compreender a relação das crianças com a água é tão importante para o ensino vivenciado e experimentado localmente, quanto para as diretrizes e programas curriculares, que muitas vezes são realizados sem a contribuição dos atores principais, que são os jovens. Também é salientado que muitos desses conhecimentos são adquiridos através da educação não formal, ou seja, da educação que recebem em casa, com a família e que devem ser levadas em conta na realização de políticas públicas e na gestão municipal do recurso. Portanto, as perguntas que norteiam essa pesquisa são: $O$ que as crianças lembram primeiro quando são estimuladas a desenhar sobre a temática água? Quais representações que emergem sobre a água como elemento indispensável para todas as vidas do planeta? São capazes de representar as mudanças do estado físico da água? Representam a chuva e o seu papel para o abastecimento? As crianças representam a água nos momentos de lazer?

Para responder a todas estas questões, o presente estudo analisará os desenhos de crianças e adolescentes que residem próximas do rio Pirai, no bairro Vila Nova em Joinville. Jovens cidadãos, com direito de participação na gestão de um rio. 
Acredita-se que através de atividades desenvolvidas na educação formal, é possível reverter algumas situações, mas antes de lançar conteúdos, é necessário verificar quais são os conhecimentos sobre a temática água que crianças e adolescentes possuem, o que pensam, o que sentem e como se posicionam diante do uso deste bem que é vital para os seres vivos e se existem diferenças desses conhecimentos segundo o gênero e a idade.

Através da investigação dos conhecimentos sobre a temática água das crianças e adolescentes, habitantes de uma região ribeirinha, poder-se elaborar recursos didáticos e pedagógicos para atividades direcionadas nas disciplinas de Educação Ambiental, Ciências, Geografia, Artes e outras que integrem a temática em seus conteúdos. Atividades estas que vão ao encontro dos anseios dos jovens dessa região e de outras regiões próximas dos rios.

\section{CONTEXTUALIZAÇÃO DA ÁREA DE ESTUDO}

Joinville está localizada na região Nordeste do estado de Santa Catarina (Latitude: $26^{\circ}$ 18' 16" S e Longitude:48 50' 44" O), com uma atitude de 3 metros acima do nível do mar (IBGE, 2019, Figura 1). Ocupa uma área de $1.120 \mathrm{Km}^{2}$, às margens da Baía da Babitonga. A população está estimada em 590.466 habitantes segundo estimativa do Instituto Brasileiro de Geografia e Estatística - IBGE (2019).

A cidade está inserida no bioma de Mata Atlântica e é na Serra do Mar que nascem os rios que abastecem a região, fazendo do Rio Piraí o objeto desse estudo, pois as crianças e adolescentes participantes da presente pesquisa residem próximas a bacia do Rio Piraí. O rio fornece $30 \%$ da água consumida na cidade e mantém a rizicultura, uma das mais importantes atividades agrícolas do local, degradando quimicamente as suas águas depois de alguns quilômetros de sua nascente (STIMAMIGLIO, 2002). 
Figura 1 - Localização da cidade de Joinville no mapa do Brasil e de Santa Catarina.

Abaixo, o mapa de Joinville e a localização do Rio Pirai. Ao lado, a Bacia do Rio Pirai, a localização do Bairro Vila Nova, local de residência dos participantes da pesquisa.

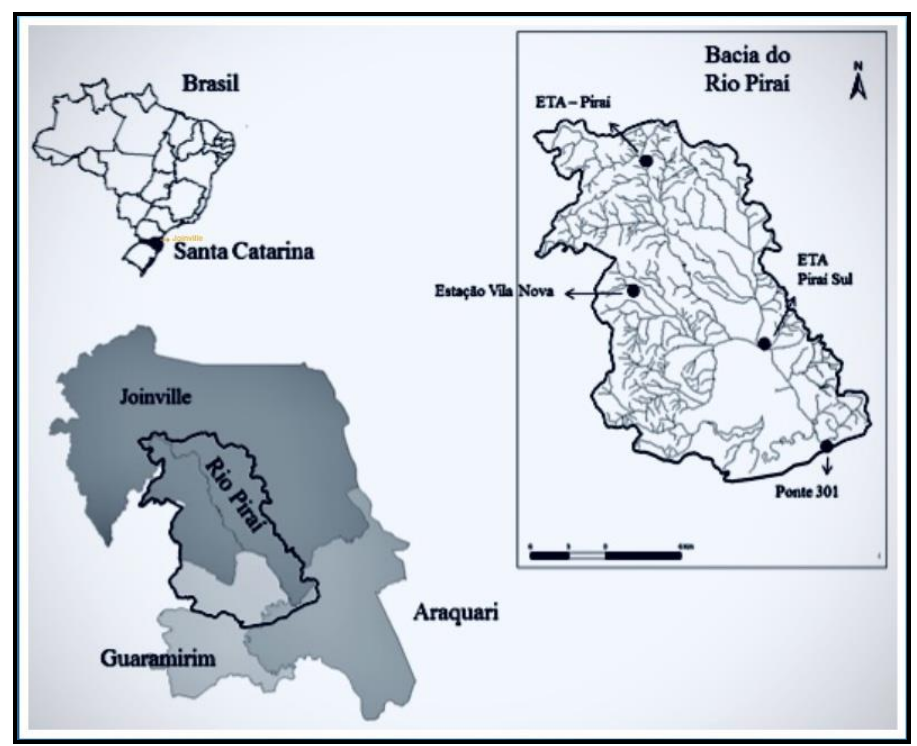

Fonte: Adaptado de Carla Schwarz: Análise Hidrológica da bacia do Rio Piraí, TCC - UFSC, 2017

\section{PROCEDIMENTOS METODOLÓGICOS}

A pesquisa foi realizada com 192 crianças e adolescentes com idades entre $7 a$ 13 anos, sendo 89 meninas (46\%) e 103 meninos (54\%), alunos da escola Bernardo Tank, do bairro Vila Nova. A escola conta com aproximadamente 600 alunos, atingindo $32 \%$ da população total. Como trata-se de uma pesquisa qualitativa, o fator saturação foi determinante para se parar com a aplicação dos desenhos (GLASSER; STRAUSS, 1967).

A frase de chamada foi: "Desenhe tudo que lhe vêm em mente quando falamos a palavra água". Uma frase de justificativa foi solicitada no verso do desenho. Nas situações em que as crianças ainda não tinham domínio da escrita, elas expressaram oralmente o seu comentário sobre o desenho e a professora ou a pesquisadora anotaram no verso da folha.

Primeiramente foram classificados os elementos desenhados, como chuva, peixes, vegetação, praia, rio, cascata, entre outros. Procurou-se dar uma atenção ao elemento representado e sua relação com a água em toda a sua amplitude e não foi avaliada a qualidade dos traços desses elementos. Ressalta-se que os dados foram 
analisados por meio de uma abordagem qualitativa, mas muitos dados podem ser quantificados, como a quantidade de pessoas que retrataram a chuva. Posteriormente foi analisado o contexto do desenho e feito a classificação por temas. Para tal, foi levado em conta os valores sobre a água e se estes valores são diferenciados segundo a idade e o gênero.

A análise dos temas e das informações coletadas têm expostos os núcleos de sentido que compõem uma comunicação (Minayo, 1993), cuja presença ou frequência tenha significado para o objeto analítico propendido, que nesse caso é a água com todas as suas especificidades e valores. Na análise das temáticas que surgiram espontaneamente, foram verificadas cinco categorias por ordem de importância nas citações: I) a água como importante elemento para a vida dos humanos e para a biodiversidade local; II) a chuva como elemento importante para o abastecimento de mares, rios e cachoeiras; III)mudanças no estado físico e o desperdício de água; IV) a água como elemento importante para as atividades lúdicas e nos momentos de lazer e, V) a poluição da água.

\section{RESULTADOS E DISCUSSÃO}

\subsection{0s elementos desenhados}

Ao todo, foram desenhados 1865 elementos, sendo que os meninos representaram 1038 e as meninas 827 elementos. Este resultado pode estar associado ao fato de os meninos terem vivências mais livres, em contato com a natureza e assim podem representar um maior número de elementos dessa realidade vivenciada por eles, como os barcos, os pássaros, as pandorgas, o sol, a chuva, a montanha (Figura 2a; b; c; d). Schwarz et al., (2016) também verificaram que os meninos desenham um maior número de elementos que as meninas em uma pesquisa que desenvolveram com crianças e adolescentes entre 6 e 14 anos de uma comunidade rural de Francisco Medrano, no México. 
Figura 2 - Amostra de desenhos e elementos representados pelos meninos

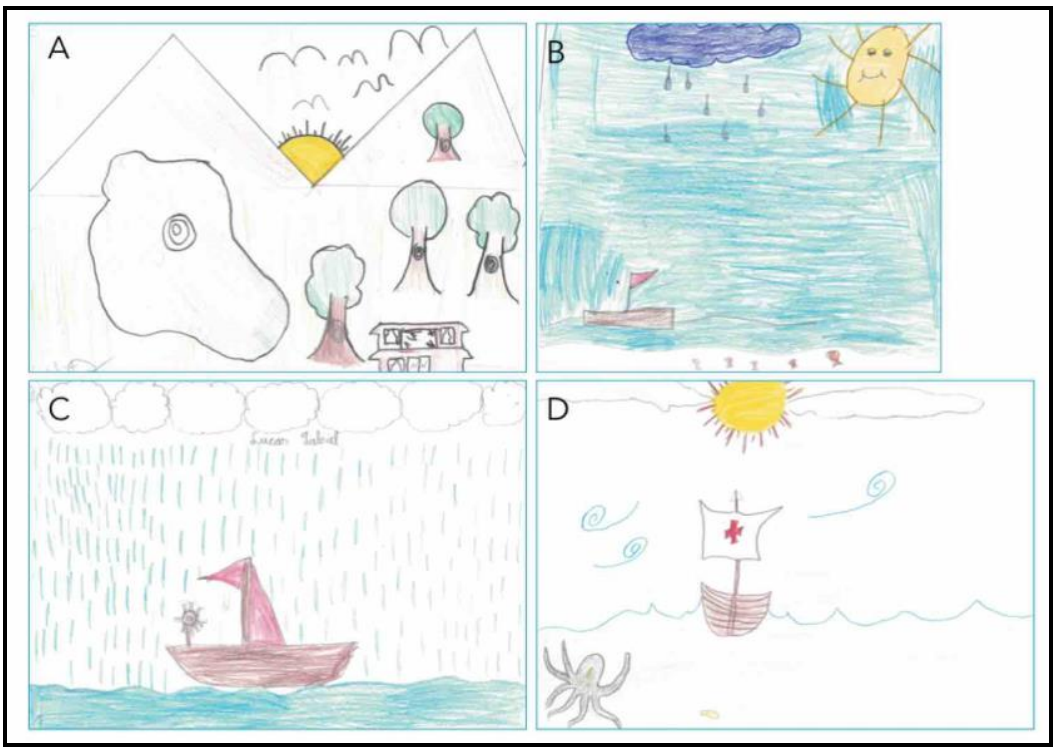

Fonte: Acervo particular dos autores (julho de 2018)

A imaginação tem sido observada como elemento nos desenhos das crianças. Vygotsky (1966) enfatiza a importância da imaginação para dar um novo significado à experiência dos indivíduos. A capacidade de imaginar contribui para o desenvolvimento da criança, expandindo seus limites e suas percepções daquilo que não vivenciou de forma direta, mas conseguiu assimilar. Contudo, Vygotsky não faz diferenciação entre os gêneros quando caracteriza o imaginário infantil.

Os desenhos das meninas apresentam elementos mais simbólicos, tais como sereia, coração, peixe, borboleta, castelo, frutas, o que revela maior fantasia na sua composição (Figura 3; e; f; g; h; i). Pode-se verificar pelas ilustrações, que os espaços femininos frequentados são representados por imagens relacionadas a atividades desenvolvidas pelas mulheres das suas famílias, como fazer comida e cuidar da horta. As diferenças estão ligadas à criação de espaços predominante femininos. Esses resultados remetem aos estudos de Bourdieu (1996) quando o autor se refere à importância das relações de "influência e de subordinação" dentro de uma estrutura de poder. Nesse sentido, as representações sobre a natureza ou, mais especificamente, a água, são o resultado de um tecido social patriarcal que acabam por moldar a cultura e os valores de mulheres e homens. As meninas representaram também elementos presentes em suas casas como o chuveiro, a torneira, o copo 
d'água (Figura 3a; c; d) denotando o uso da água em atividades domésticas, também representadas pelas crianças mexicanas da região de Francisco Medrano e relatadas nos trabalhos de Schwarz et al., (2016).

A inserção da presença humana ocorreu em maior número nos desenhos dos meninos, enquanto as meninas desenharam mais peixes e frutas, quando evocadas a desenharem tudo que Ihes vinha em mente quando se fala em água.

\section{Figura 3 - Amostra de desenhos e elementos representados pelas meninas}

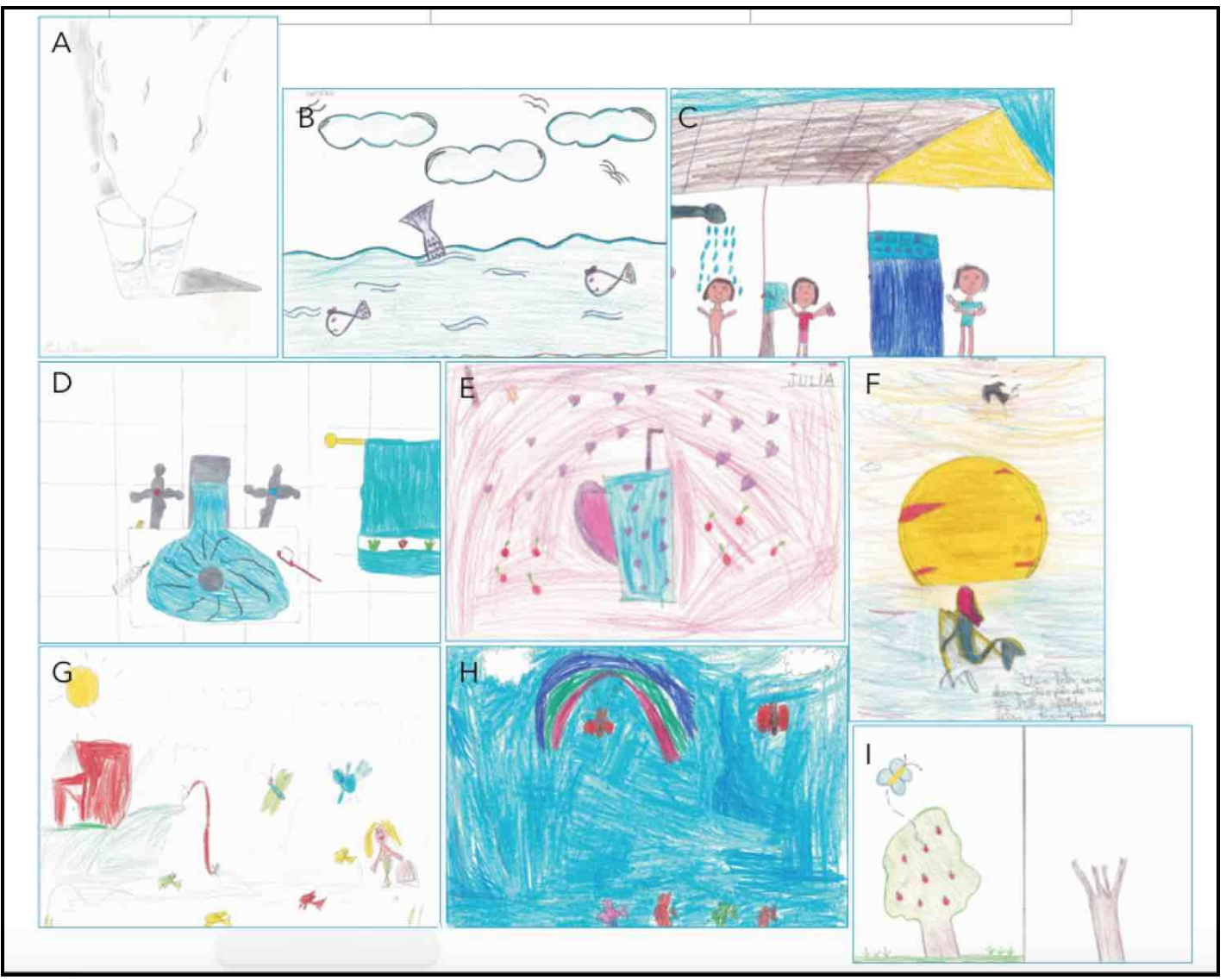

Fonte: Acervo particular dos autores (julho de 2018)

Observa-se nestas imagens a visão da água como um recurso a ser utilizado pelo ser humano. Um comentário feito no verso do desenho por uma menina de 11anos foi "A água serve para várias coisas, tomar banho, lavar carro, lavar louça, encher piscinas etc. Mas o mais importante é ter ela para beber porque o ser humano não sobrevive sem água". Mesmo reconhecida como um patrimônio, percebe-se a continuidade da visão utilitarista da água. O discurso predominante nas escolas é permeado pela defesa da racionalização do seu uso, mas destaca-se a necessidade de 
disciplinas ligadas à educação patrimonial, que contribuam para que seja questionada essa ideia utilitarista ainda marcante na sociedade. Essa visão põe a gestão da água mais a serviço das demandas do mercado do que de políticas de preservação de fato de um patrimônio fluvial. Como diz Leff, (2003, p. 22), a natureza continua a ser desnaturalizada e convertida em recurso.

As crianças representaram primeiramente, os elementos naturais como as águas da chuva, que em alguns casos está molhando as plantações e as flores (Figura 4a; b; d; i; k). Também representaram cachoeiras, os rios (Figura $4 \mathrm{~d}$; i; j), os peixes (Figura 4j), o oceano (Figura $4 \mathrm{~m}$ ); a praia, as ilhas (Figura $4 \mathrm{f}$ ); Em seguida, os elementos humanizados, como os barcos (Figura 4l; m), as torneiras, chuveiros (Figura4 c; g); casas (Figura a;) foram representados. Muitos desenhos podem abranger vários elementos que contextualizam toda uma ideia representada sobre a água e a sua importância (Figura 4).

Figura 4 - Amostra dos elementos representados pelos jovens de 6 a 13 anos de idade, residentes do Bairro Vila Nova, Joinville-SC.

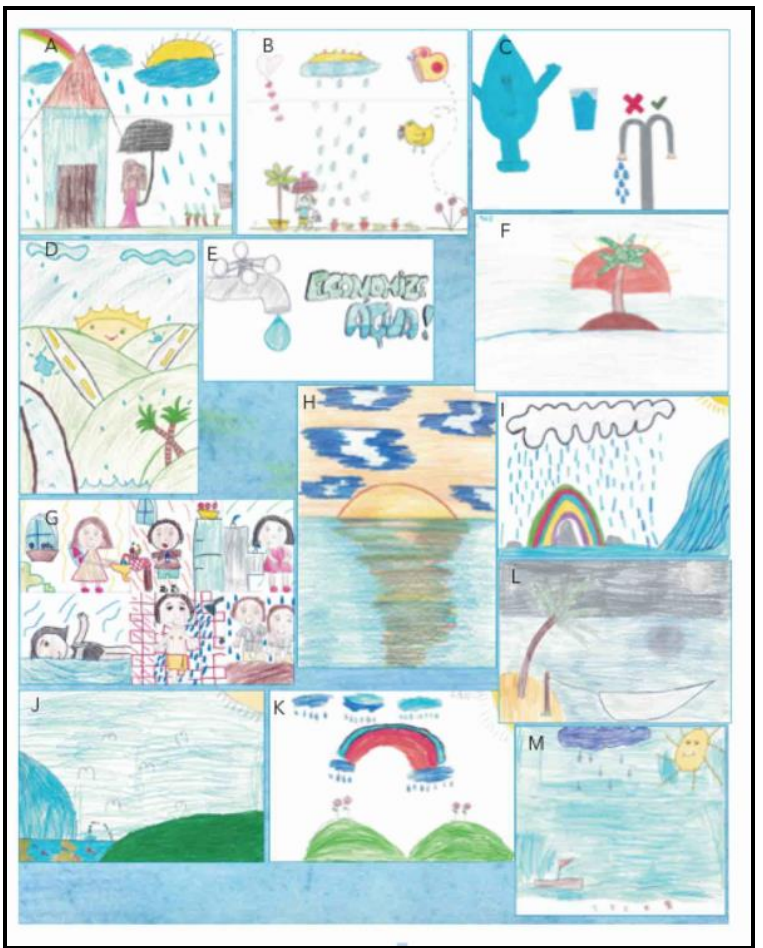

Fonte: Acervo particular dos autores (julho de 2018) 
Observa-se que tanto as crianças de 7 a 9 anos, quanto as de 10 a 13 anos, representaram em número significativo, os rios e as cachoeiras, fato que pode estar relacionado às suas vivências, já que na localidade onde moram, está situado o rio Piraí e uma cascata de mesmo nome. A chuva é um elemento fortemente representado, podendo estar relacionado ao tempo chuvoso que é frequente na região. O oceano aparece em menor frequência, sugerindo que eles frequentam as praias litorâneas ocasionalmente. Segundo Mubarac Sobrinho (2011, p.148) "o cotidiano e as falas das crianças representam muito mais do que uma simples reprodução da realidade [...], elas resinificam, reinventam as coisas e dão sentido peculiar as suas formas de entender o mundo e o lugar onde moram". A representação é as vezes produto e processo, pois ela é o resultado de um ato cognitivo baseado sobre a realidade social, quanto ao produto, ele é ativo, pois contribui a orientar e organizar o ato de cognição, mas assim como a sociedade e as práticas dentro da mesma evoluem, as representações também sofrem transformações (AUDIGIER, 1994).

Na mesma linha de pensamento Schwarz $(2016$, p.8) também observou em seus estudos que "a criança, independentemente de sua idade, revela o que de mais importante ela aprendeu e experimentou de seu ambiente local, bem como os elementos que são mais significativos para sua vida [...]".Na concepção de Tuan (2011, p.11) o "lugar é qualquer localidade que tem significado para uma pessoa ou grupo de pessoas". Pode-se afirmar que as crianças desenharam rios e cachoeiras primeiramente em razão da afinidade que possuem com esses elementos e evidentemente com os outros também que apareceram nessas representações.

Pode-se entender, portanto, que as representações das crianças sobre a água envolvem também elementos culturais. De acordo com os Parâmetros Curriculares Nacionais (1997), o lugar é um dos conceitos fundamentais para reconhecer a natureza como habitat do ser humano. O conhecimento sobre os lugares contribui para a construção de imagens que passam a fazer parte da cultura do indivíduo. É 
necessário trabalhar primeiramente com paisagens e problemas locais, para depois passar a trabalhar com problemas planetários, levando formação de sujeitos participantes da prática social em seus espaços de vida (PRADO; CARNEIRO, 2017). O lugar onde a criança vive acaba por constituir-se o meio pelo qual ela vê o mundo, como afirma Santos (2005, p.158), "define-se como funcionalização do mundo e é por ele (lugar) que o mundo é percebido empiricamente". Neste sentido, Castellar (2000, p. 32) também afirma que "toda informação fornecida pelo lugar ou grupo social no qual a criança vive é altamente instigadora de novas descobertas".

A partir dos resultados apresentados, é possível ponderar que as crianças e os adolescentes ilustram em seus desenhos o contexto em que vivem, apresentando as representações do lugar e da cultura da sua comunidade, inserindo nela as percepções sobre a água como um bem de consumo.

Na sequência, a água será contextualiza e apresentada em diferentes temas, esses temas fluíram naturalmente através da frase de chamada: a partir de uma classificação feita através dos desenhos de crianças e adolescentes.

\subsection{A água contextualizada e classificada em importantes temas}

Primeiramente foram classificados e analisados os principais elementos representados, quando as crianças foram motivadas a falar sobre o tema através da frase de chamada: "desenhe tudo que lhe vêm em mente quando falamos sobre água". Esses temas surgiram de forma espontânea através da frase de chamada. A justificativa no verso do desenho também norteou o pertencimento da obra na temática correspondente. Ao todo foram representados cinco temas que serão expostos a seguir, segundo a frequência e consequentemente a importância dessas representações. 
I) A água como importante elemento para a vida dos humanos e da biodiversidade local

A importância da água para a vida foi desenhada 79 vezes, cerca de 41,14\% nos trabalhos analisados. O ser humano aparece bebendo a água (Figura 5c), pescando seu alimento no rio (Figura 5b), molhando a horta de sua casa (Figura $5 d$, e). Os desenhos podem estar representando atividades do cotidiano que as crianças e suas famílias costumam realizar (Figura 5b, c).

Figura 5 - Amostra dos desenhos que remetem a água como importante elemento e indispensável para todas as formas de vida do Planeta: meninas e meninos entre 7 a 13 anos, residentes no Bairro Vila Nova, Joinville-SC.

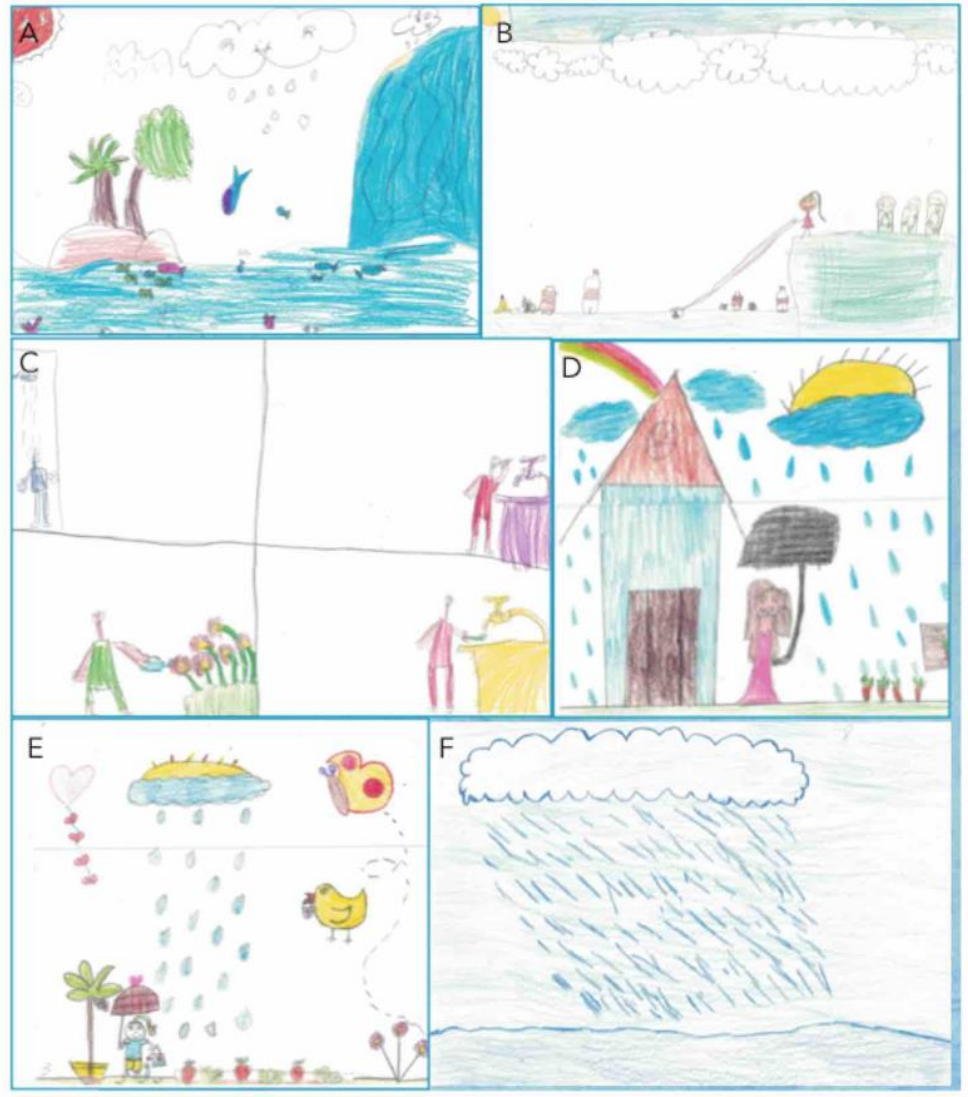

Fonte: Acervo particular dos autores (julho de 2018).

As crianças e adolescentes perceberam que, além do homem, as outras formas de vida também dependem da água. Os animais e as plantas aparecem de forma significativa usufruindo deste recurso. 
Nas ilustrações, estão representadas atividades cotidianas das famílias com a utilização da água para a alimentação de maneira indireta, por meio da pesca ou da produção de hortaliças, o que exige irrigação. Houve relação entre o uso da água e a manutenção da fauna e da flora local. Importante lembrar que o ambiente que as crianças vivem tem a presença de animais e a região está inserida no Bioma Mata Atlântica, com áreas preservadas.

Uma pesquisa realizada por Junqueira (2014), constatou que a vegetação em uma parte do bairro Vila Nova é densa, auxiliada pela conformação geográfica. Grande parte das margens de rios, riachos e córregos, têm suas áreas verdes preservadas atendendo ao que determina a Lei Federal: Lei $n^{\circ} 12.651$, de 25 de maio de 2012 do Código Florestal (BRASIL, 2012). Contudo, há trechos com rios canalizados, com vias próximas aos cursos d'água ou sem a preservação da mata ciliar. As maiores concentrações de cobertura vegetal estão nas porções dotadas de morros altos e encostas íngremes. Em alguns trechos, próximos as margens de rios há ocupação.

Bacci e Pataca (2008) destacam a água como elemento essencial para a vida no planeta e para o equilíbrio da biodiversidade. Da mesma forma, a Agência Nacional de Águas - ANA (BRASIL, 2011) enfatiza que a boa qualidade da água é vital não somente para a existência humana, mas para toda a vida animal e vegetal, essa ligação inerente, vital e indispensável foi retratada primeiramente nesses desenhos.

II) A chuva como elemento importante para o abastecimento de oceanos, rios e cachoeiras

Nesta temática os alunos retratam a chuva como um elemento importante e representada em 40 desenhos (20,83\%), abastecendo oceanos, rios, cachoeiras e nascentes, contribuindo para a vazão dos rios (Figura 6a; c) e para que os peixes, animais e plantas mantenham-se vivos (Figura 6b). Há situações em que a chuva é 
retratada em forma de temporal com relâmpagos (Figura 6c), o que pode ser explicado pela frequência com que esse tipo de fenômeno ocorre na cidade em que os jovens vivem, especialmente no verão. Sobre este tema foram identificados 22 desenhos de meninas e 18 de meninos.

Figura 6 - Amostra dos desenhos que remetem a chuva como elemento importante para o abastecimento de oceanos, rios e cachoeiras: meninas e meninos entre 7 a 13 anos, residentes no Bairro Vila Nova, Joinville-SC

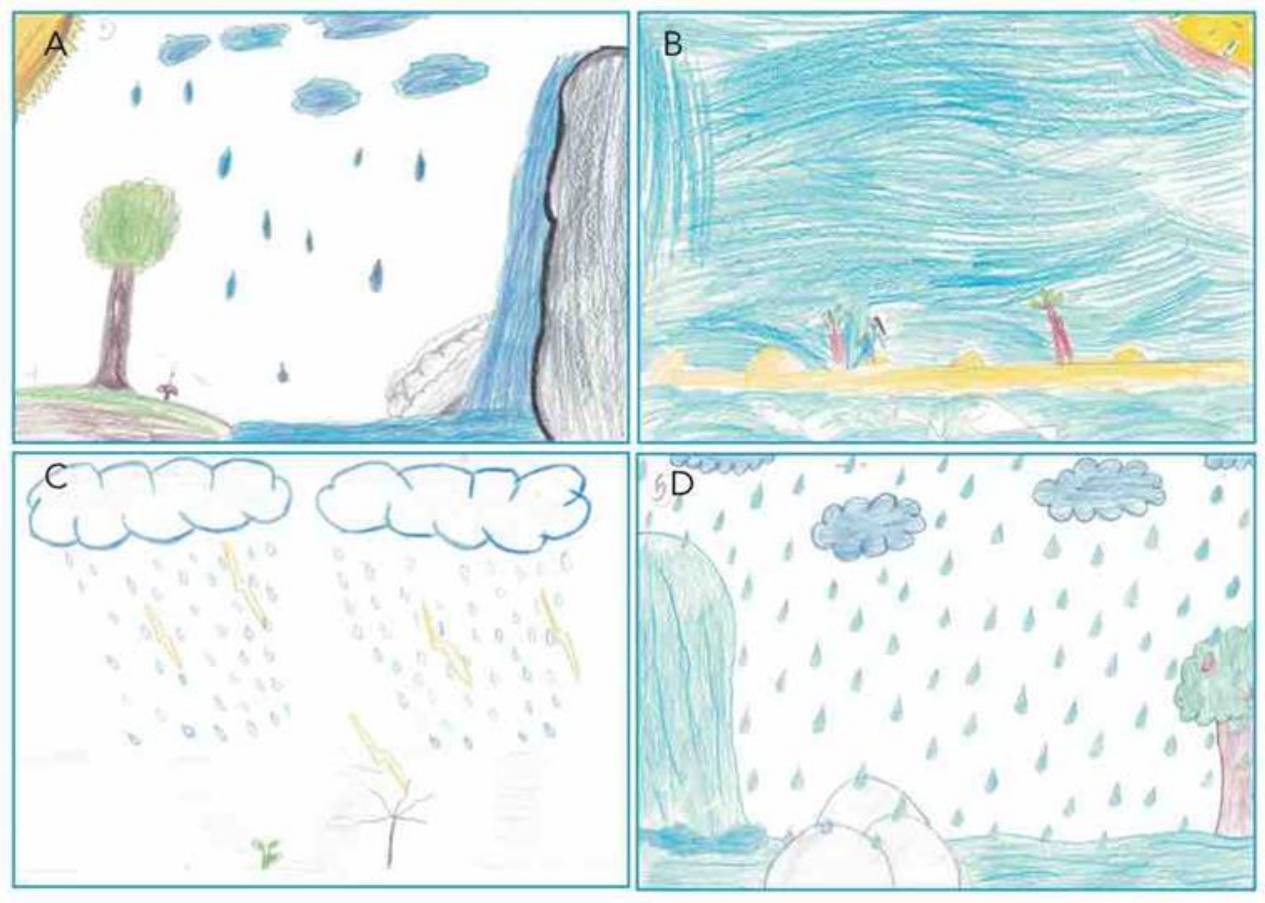

Fonte: Acervo particular dos autores (julho de 2018).

\section{III) Mudanças no estado físico e o desperdício de água}

No que se refere à abordagem sobre mudanças no estado físico e o desperdício, de água, tanto os meninos quanto as meninas demonstraram grande preocupação com o desperdício, perfazendo 38 ilustrações, cerca de 19,79 \%. As meninas ilustraram esta problemática em imagens que mostram o quanto a água é importante e como ela faz falta em momentos de escassez. Essas situações apareceram em 22 desenhos que mostram a dificuldade de realizar tarefas em casa quando não tem água. Também houve a questão das lágrimas de tristeza na ausência 
deste recurso: "Quando me falam a palavra água, eu penso em natureza, rios, árvores, em tudo que precisa da água para se formar, e as lágrimas não são de felicidade ou de tristeza e sim do que a pessoa estiver sentindo" (comentário de uma menina de 12 anos).Os meninos também focaram esta questão em 16 desenhos e fizeram comentários como "evite o desperdício", descrevendo e sugerindo através das imagens, ações para economizar água. Foram retratadas situações de seca nas quais não há vida.

A preocupação demonstrada nos desenhos também aparece na mídia e literatura local. No Brasil, cerca de 907 municípios sofrem com a escassez total ou parcial de água e a crise não se resume ao Nordeste (BARBALHO, 2018). Em estudos realizados por Schmitz e Bittencourt (2017), toda a água disponível para a região metropolitana de São Paulo está quantitativamente comprometida até o ano de 2020. Em regiões fortemente industrializadas a demanda pelo recurso é ampliada e é necessário realizar estratégias que possam auxiliar na ampliação da melhoria dos sistemas de tratamentos de efluentes que elevariam a qualidade das águas (Schmitz; Bittencourt, 2017).

Em Santa Catarina são frequentes os períodos de estiagem, e a vazão diminui, comprometendo o abastecimento de água, como o que aconteceu em setembro de 2017 (Centro de Informações de Recursos Ambientais e de Hidrometeorologia de Santa Catarina - CIRAM). Joinville também sofreu com essa estiagem. O Rio Pirai, no bairro Vila Nova igualmente teve sua vazão reduzida, preocupando os moradores e a Companhia de Águas de Joinville (GIRARDI, 2017). Outras estiagens ocorreram em agosto de 2015, quando o mesmo rio estava com $19 \%$ abaixo do considerado ideal segundo a Companhia de Águas de Joinville, prejudicando o abastecimento de 13 bairros da cidade (SILVA, 2015). Segundo Bonin (2013), ocorreram 1.518 registros de falta de água no período de 1991 a 2012 no Estado e foram 227 municípios atingidos pela falta de água. 
IV) A água nas atividades lúdicas e nos momentos de lazer

Os momentos de lazer com brincadeiras foram retratados em vinte e oito ilustrações (28), cerca de 14,58\%, sendo 17 de meninos que mostraram a si próprios usando a mangueira para se refrescar e brincar (Figura 7), nadando no rio ou surfando no oceano (Figura 7f), descendo pelo tobogã (Figura 7d), passeando com a família na cascata do Piraí (Figura 7b). Os desenho e comentários dos meninos também retrataram atividades recreativas realizadas com suas famílias ou amigos (Figura 7a; b; d; e).

As meninas por sua vez, retrataram em 11 desenhos atividades lúdicas, sendo que a figura da sereia nas águas apareceu em seis deles (Figura 7c). Observou-se que a imaginação está presente nas imagens e nos comentários, denotando que elas brincam. Também foram retratadas pessoas na piscina utilizando a água em momentos de descontração.

Figura 7: Amostra dos desenhos que remetem a água nas atividades lúdicas e nos momentos de lazer: meninas e meninos entre 7 a 13 anos, residentes no Bairro Vila Nova, Joinville-SC.

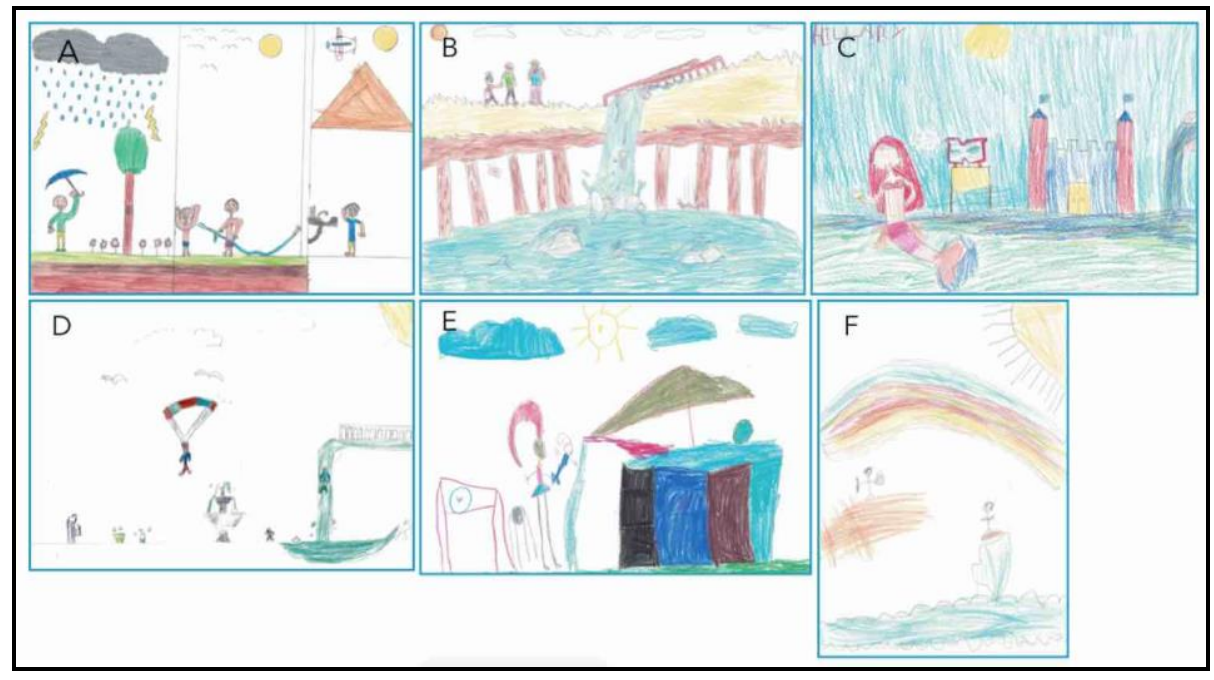

Fonte: Acervo particular dos autores (julho de 2018)

$\mathrm{Na}$ abordagem deste tema os meninos focaram mais os passeios e as brincadeiras e as meninas lembraram mais de figuras imaginárias como a sereia. Isso pode estar relacionado aos hábitos das famílias, pois os meninos desenvolvem mais 
atividades ao ar livre como nadar ou pescar com os pais. Para Derdik (1989, p. 115) "o desenho configura um campo minado de possibilidades, confrontando o real, o percebido e o imaginário. A observação, a memória e a imaginação são as personagens que flagram essa zona de incerteza: o território entre o visível e o invisível".

\section{V) A poluição das águas}

A poluição das águas teve um índice menor de menções nas ilustrações (sete), cerca de 3,64 \%. Poucos meninos (quatro) demonstraram preocupação em seus comentários e desenhos com a poluição das águas. Um deles desenhou duas telas demonstrando sua visão de que na parte de um rio em que há poluição, onde os peixes estão mortos, já na água cristalina os peixes estão brincando e se alimentando.

Figura 8 - Amostra dos desenhos que remetem a poluição das águas: meninas e meninos entre7 a 13 anos, residentes no Bairro Vila Nova, Joinville-SC.

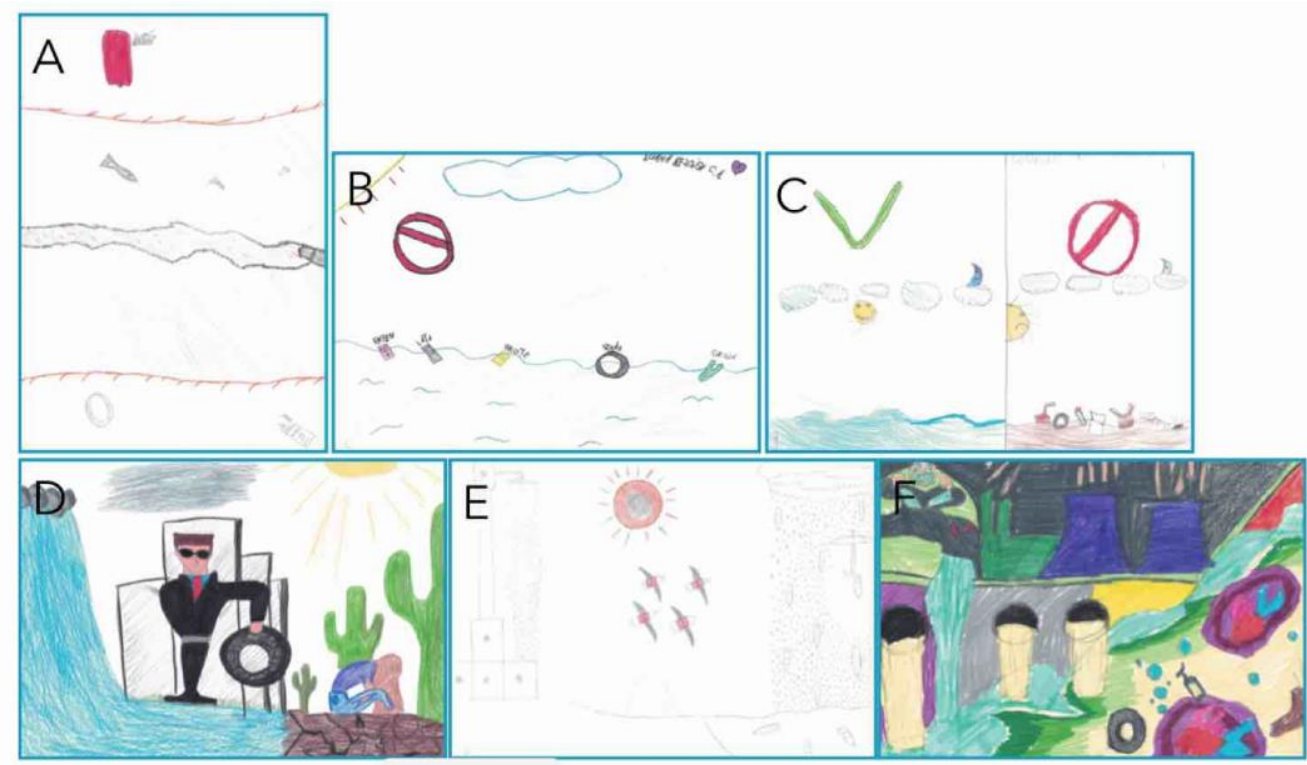

Fonte: Acervo particular dos autores (julho de 2018).

O menino expressou suas ideias da seguinte forma: "Eu desenhei duas telas: uma errada e a outra certa. A errada tem um rio cheio de lixo e um peixe morto. E na 
certa eu desenhei uma água cristalina e bem linda, cheia de peixinhos bonitinhos" (Figura 8c).

Da mesma forma, foram mostrados dois lados de uma praia, um poluído e sem vida e outro limpo e com vida marinha (Figura 8a); outro desenho mostra que a poluição irá alterar todo ciclo da água (Figura 8c).

As meninas, por sua vez, também revelaram em três desenhos e seus comentários uma certa preocupação em relação aos danos causados à água pela poluição. Estas figuras ilustram pessoas tendo contato com a água em atividades de lazer e, por isso é preciso que a água esteja limpa; objetos lançados nos corpos d'água como pneus, sacola e lata é um símbolo indicativo de que isso é proibido (Figura 8b); um homem rico, que tem boas condições de vida e fácil acesso à água com um pneu nas mãos jogando no leito de uma cascata, enquanto uma pessoa pobre que mora em uma região seca chora pela falta deste recurso (Figura 8d).

A preocupação com a poluição das águas, que foi pouco evidenciada, pode estar relacionada ao acesso que eles têm ao rio Piraí que não apresenta poluição perceptível e eles podem desfrutar de banhos frequentes nas águas desse rio. As meninas que desenharam sobre poluição, centralizaram-se mais nos problemas sociais do presente, como o consumismo que descarta o lixo nas águas, o acesso a este recurso, enquanto os meninos apresentaram situações que envolvem as consequências no futuro da humanidade a partir da poluição dos rios e oceanos. Nesta perspectiva Machado (2004, p.422), alerta para a problemática da poluição dos mananciais que vem ocorrendo com o crescimento da população e a industrialização:

O uso da água não pode ser apropriado por uma só pessoa física ou jurídica, com exclusão absoluta dos outros usuários em potencial; o uso da água não pode significar a poluição ou a agressão desse bem; o uso da água não pode esgotar o próprio bem utilizado e a concessão ou a autorização (ou qualquer tipo de outorga) do uso da água deve ser motivada ou fundamentada pelo gestor público.

Também pode-se sugerir que as discussões sobre os problemas ambientais, incluindo a poluição dos rios, são mais intensas nos conteúdos do ensino médio, por essa razão essa questão foi pouco representada pelas crianças participantes. Contudo, a poluição dos rios precisa ser evitada, sendo este um problema global. Daí a 
importância de programas de ensino que enfatizem essa problemática, oportunizando às crianças e aos adolescentes a participação em discussões que contribuam para seu melhor entendimento. As Diretrizes Curriculares Nacionais (BRASIL, 2017) destacam a necessidade de que a educação ambiental seja estudada na educação formal, incluindo a problemática da poluição das águas, que vem se tornando cada vez mais preocupante.

\section{CONSIDERAÇÕES FINAIS}

Este artigo tentou mostrar, de maneira não exaustiva, o quanto o desenho é um importante instrumento para recolher as representações sociais de crianças e adolescentes sobre temáticas ambientais. Nesse caso, procurou-se analisar os conhecimentos sobre a água em seu amplo e vasto sentido, utilidades e anseios. As representações são bastante cognitivas, ou seja, os indivíduos necessitam refletir muito antes de desenhar. Essa prática pode ser utilizada para buscar os conhecimentos científicos em diversas disciplinas, como em Geografia, Ciências, Biologia, História, Artes e tem uma grande vantagem, uma vez que os jovens adoram se expressar através do desenho. Nesse estudo, foram analisadas as representações sociais sobre a água, de crianças e adolescentes entre 7 a 13 anos, residentes de uma região próxima ao rio Pirai, importante rio que abastece $30 \%$ da cidade de Joinville.

Desenhos que remetem a água como importante líquido que sacia a sede dos diversos seres, foi primeiramente citado. É possível verificar nesses desenhos algumas práticas, como os indivíduos se hidratando, regando flores, verduras e legumes. O segundo tema mais bem representado foi a chuva como elemento importante para o abastecimento de oceanos, rios e cachoeiras. Em muitas ilustrações, foram retratados os temporais que são frequentes na região e essas representações corroboram com a afirmação de que a representação social está impregnada de situações vivenciadas cotidianamente.

Os cuidados com água e os problemas relacionados a poluição foram minimamente desenhados e fornecem importantes pistas para que os conteúdos 
programáticos reforcem essas questões. Não somente na educação formal, mas também com atividades estabelecidas pela gestão municipal local. Programas estes que devem promover a importância e os cuidados com os rios da cidade e que envolvam a comunidade. Para que os valores extremamente utilitaristas, observados nesse estudo, se transformem em valores mais humanistas, ecológicos e de um bem comum.

\section{REFERÊNCIAS}

ANTONELLI, M. GILMONT, M.; ROSON, R. Water's Green Economy: Alternative Pathways for Water Resource Development in Agriculture, L'Europeen Formation, n. 365 p. 23-47, 2012/2013.

AUDIGIER, F. Des élèves, des villes: représentations sociales et didactique. Révue de Géographie de Lyon, v. 9, n. 6, p. 205-219., 1994.

BACCI, D.C.; PATACA, E.M. Educação para a água. Estudos Avançados, v.63, n. 22, p.211 226, 2008.

BAECHLER, L. La bonne gestion de l'eau: un enjeumajeur du développement durable, L'Europe en Formation, n. 365, p. 3-21, 2012/2013.

BARBALHO, H. Governadores e ministro da Integração Nacional discutem crise hídrica no Brasil. FÓRUM MUNDIAL DA ÁGUA, 8., 2018, Brasília. Painel... Disponível em: https://www.agenciabrasilia.df.gov.br/2018/03/20/governadores-e-ministro-da-integracaonacional-discutem-crise-hidrica-no-brasil/. Acesso em: 21 mar. 2018.

BARRAZA, L. Children's drawing about the environment. Journal Environmental Education Research, v. 5, n. 1, p. 49-67, 1999.

BONIN, G. Atlas brasileiro de desastres naturais: 1991 a 2012. 2 ed. Florianópolis: CEPED, 2013.

BOURDIEU, P. A ilusão biográfica. In: AMADO, J.; FERREIRA, M. de M. (Org.). Usos e abusos da história oral. Rio de Janeiro: Editora da FGV, 1996, p.183-191.

BOWKER R. Children's Perceptions and Learning About Tropical Rainforests: An Analysis of Their Drawings, Environmental Education Research, v.13, n. 1, p. 13: 75-96, 2007.

BRASIL. Agência Nacional de águas - ANA. Programa das Nações Unidas para o Meio Ambiente Cuidando das águas: soluções para melhorar a qualidade dos recursos hídricos. Brasília: ANA, 2011. 
BRASIL. Presidência da República, Casa Civil. Lei 12.651, de 15 de Maio de 2012.

BRASIL. Ministério da Educação. Secretaria de Educação Fundamental. Diretrizes Curriculares Nacionais: Brasília: MEC/SEF, 2017.

CASTELLAR, S.M.V.A alfabetização em geografia: Espaços da Escola, v. 10, n. 37, p. 29-46, 2000.

CARDOSO, J. S. A água como patrimônio comum da humanidade. Âmbito Jurídico, Rio Grande, v. IX, n. 30, jun. 2006. Disponível em: http://www.ambitojuridico.com.br/site/index.php?n link=revista artigos leitura\&artigo id=1184. Acessoem19 de mar de 2018.

DAI, A. Learning from Children's Drawings of Nature. In: Katz P. (eds) Drawing for Science Education. Roterdã: SensePublishers, 2017.

DERDIK, E. Formas de pensar o desenho: desenvolvimento do grafismo infantil. São Paulo: Scipione, 1989.

DURIF-BRUCKERT, C. Les représentations de l'eau chez les enfants, Journal des psychologues, n. 313, p. 71-76, 2013.

EMPINOTTI, V.; JACOBI, P.R.; FRACALANZA, A.P. Transparência e a governança das águas, Estudos Avançados, v. 30, n. 88, p. 63-75, 2016. Disponível em: http://www.scielo.br/scielo.php?script=sci arttext\&pid=S010340142016000300063\&lng=en\&nrm=iso. Acesso em: 15 mar. 2018.

FELICIDADE, N.; MARTINS, R.C.; LEME, A.A. A água como valor social: considerações acerca de uma prática acadêmica em torno do tema. In: Felicidade, N.; Martins, R. C, (Eds). Uso e gestão dos recursos hídricos no Brasil. São Carlos: Rima, 2000. p. 3- 15, 2001.

FREIRE, P. Pedagogia do oprimido. Rio de Janeiro: Paz e Terra, 1994.

FRÖHLICH, C.J. Water: Reason for Conflict or Catalyst for Peace? The Case of the Middle East. L'Europeen Formation, n. 365, p.139-161, 2012/2013.

GARRÉ, B.H. HENNING, P.C. Discurso da crise ambiental na mídia impressa. Educação em Revista, $\quad$ v. 33, p.1-20, $2017 . \quad$ Disponível em: http://www.scielo.br/scielo.php?script=sci_arttext\&pid=S010246982017000100104\&lng=en\&nrm=iso Acesso em 02 de mar de 2018.

GLASER, B.; STRAUSS, A. The discovery of grounded theory: Strategies for qualitative research. New York: Aldine Publishing Company, 1967.

GIRARDI, A. Estiagem prolongada baixa nível do rio Pirai: Circulando na Vila. Setembro de 2017. Disponível em: http://adilsongirardi.blogspot.com/2017/09/estiagem-baixa-niveldo-rio-pirai.html. Acesso em: 15 mar. 2018. 
HASSAN, A.R. Les Nations Unies et le problème de l'eaudansle monde: essais sur ONUEAU. 2008. 113p. Dissertação (Mestrado em Ciências Políticas) - Université du Québec à Montréal, Département des Sciences Politiques, Montréal, QC, (Canadá).

JACOBI, P.R. EMPINOTTI, V.L. SCHMIDT, L. Escassez Hídrica e Direitos Humanos. Revista Ambiente \& Sociedade, v. 19. n. 1, p.1-5, 2016.

JUNQUEIRA, J.R. Análise da evolução das áreas verdes urbanas - Vila Nova - Joinville/SC. In: I CONGRESSO BRASILEIRO DE CADASTRO TÉCNICO MULTIFINALITÁRIO-COBRAC, Florianópolis. Anais. Florianópolis: UFSC, 2014. p. 1-12

KING, D. Doing Their Share to Save the Planet: Children and Environmental Crisis. New Brunswick, USA: Rutgers University Press, 1995.

LASSERRE, F. Le partage de l'eau dans le monde: un enjeumajeur du xxie siècle. Mélanges de la Casa de Velázquez, v. 36, n. 2, p. 171-183, 2006.

LEFF, E. A complexidade ambiental. São Paulo: Cortez, 2003.

LUQUET, G.H. O desenho infantil. Porto: Livraria Civilização, 1969.

MACHADO, C.J.S. Recursos hídricos e cidadania no Brasil: limites, alternativas e desafios, Ambiente e Sociedade, v. 6, n. 2, p. 121-136, 2003.

MACHADO, P.A.L. Direito Ambiental Brasileiro. 12. ed. São Paulo: Malheiros, 2004.

MINAYO, M.C.S. O desafio do conhecimento. São Paulo: Hucitec, 1993.

MUBARAC SOBRINHO, R.S. Vozes Infantis Indígenas: as culturas escolares como elementos de (des) encontros com as culturas das crianças Sateré-Mawé. Manaus: Valer, 2011.

NASCIMENTO-SCHULZE, C.M. Representações sociais da natureza e do meio ambiente. Revista ciências humanas UFSC. n. 3, p. 87-61, 2000. Disponível em: https://periodicos.ufsc.br/index.php/revistacfh/article/view/24124/21519 Acesso em: 18 mar. 2018.

Organisation des Nations Unies pour l'éducation - ONU. La science et la culture. (Rapport des Nations Unies sur la mise en valeur des ressources en eau 2018), UNESCO, 2018. Disponível em: http://unesdoc.unesco.org/images/0026/002614/261466f.pdf. Acesso em: 2 mar. 2018.

PENA-GARCIA, A. Una perspectiva social de la problemática del agua. Investigaciones Geográficas, $\quad$ v. 62, p. 125-137, 2007. Disponível em: http://www.scielo.org.mx/scielo.php?script=sci_arttext\&pid=S0188$46112007000100008 \&$ Ing=es\&nrm=iso. Acesso em: 5 mar. 2018. 
PÉREZ, V.R. CRISPIN, A.F. El agua para los niños de tercero de pré-escolar del municipio de Puebla. In Forum de Sostenibilidad Revista de la Cátedra Unesco sobre Desarrollo Sostenible de la UPV/EHU, n. 2, p. 57-66, 2008. Disponível em: http://www.ehu.eus/cdsea/web/wp-content/uploads/2016/12/Revista2.pdf. Acesso em: 12. dez. 2017.

PIAGET, J. O nascimento da inteligência na criança, 4. ed. Rio de Janeiro: Guanabara, 1987.

PRADO, C.J.B. CARNEIRO, S.M. Livro didático de geografia: estudo da linguagem cartográfica. Educação \& Realidade, v. 42. n. 3, 2017. Disponível em: http://www.scielo.br/scielo.php?pid=S2175-62362017005003101\&script=sci_arttext. Acesso em: 5 mar. 2018

SANTOS, M. Da totalidade ao lugar. São Paulo: Edusp, 2005.

SCHMITZ, A.P.; BITTENCOURT, M. V. L. Crescimento econômico e pressão sobre recursos hídricos. Estudos Econômicos, v. 47. n. 2, p. 329-363, 2017. Disponível em: http://www.scielo.br/scielo.php?script=sci_arttext\&pid =S0101-

$41612017000200329 \&$ Ing $=$ en\&nrm=iso. Acesso em: 2 mar. 2018.

SCHWARZ, M.L. SEVEGNANI, L. ANDRÉ, P. Representações da Mata Atlântica e de sua biodiversidade por meio dos desenhos infantis. Ciência \& educação, v. 13, n. 3, p. 369388, 2007.

SILVA A.F. AGUIAR, JR.O. BELMIRO,C. A. Imagens e desenhos infantis nos processos de construção de sentidos em uma sequência de ensino sobre ciclo da água. Revista Ensaio, v.17. n. 3, p. 607-632, 2015.

SILVA, S.S. Da Falta de chuvas prejudica abastecimento da água em 13 bairros de Joinville. ND. Disponível em: https://ndmais.com.br/noticias/falta-de-chuvas-reduziu-em-19-onivel-do-rio-pirai-em-joinville/. Acesso em: 16. ago. 2019.

SOUZA, S.A. Água juridicamente sustentável: um estudo sobre a educação ambiental como instrumento de efetividade do programa de conservação e uso racional da água nas edificações de Curitiba/PR. Revista Meio Ambiente e Sustentabilidade, v. 1. n. 1, p. 93$114,2012$.

STIMAMIGLIO, A. Hidrografia. In: KNIE, J. L. W. (Eds). Atlas ambiental da região de Joinville: complexo hídrico da Baía da Babitonga. 2. ed. Florianópolis: FATMA/GTZ, 2002. p. 19-22.

TIBERGHIEN, F. Eau et agriculture: problématiques actuelles. Pour, n. 213, p. 37-43, 2012.

TYTLER, R. PETERSON, S.; PRAIN, V. Picturing evaporation: learning science literacy through a particle representation. Teaching Science, v. 52, n.1, p. 12-17, 2006 
TUAN, Y. Espaço, tempo, lugar: um arcabouço humanista. Geograficidade, v. 1. n. 1, 2011. VYGOTSKY, I. La imaginación y el arte em la infancia. 3. ed. Madrid (Espanha): Ediciones Akal, 1966. 